\title{
INTEGRAL REPRESENTATIONS OF PRODUCTS OF AIRY FUNCTIONS RELATED TO FRACTIONAL CALCULUS
}

\author{
Leila Moslehi AND Alireza Ansari
}

\begin{abstract}
In this paper, using the inverse Laplace transform of multi-valued functions we show new identities for the powers of Airy functions in terms of the Riemann-Liouville and Weyl fractional integrals of order $\alpha$. In this sense, we get new integral representations for the special functions including trigonometric functions in terms of the M-Wright function and Hilbert transform. Also, we get the Hadamard fractional integrals of Airy functions in terms of the Widder potential and Mellin transforms of the Volterra functions.
\end{abstract}

Mathematics subject classification (2010): 44A10, 26A33, 33C10. functions.

Keywords and phrases: Laplace transform, Airy function, Riemann-Liouville fractional integral, Bessel

\section{REFERENCES}

[1] M. Abramowitz and I. A. STEgun, Handbook of Mathematical Functions with Formulas, Graphs, and Mathematical Tables, National Bureau of Standards, Applied Mathematics, 9th printing, Dover, New York, 1972.

[2] A. Apelblat, Integral Transforms and Volterra Functions, Nova Science Publishers, New York, 2010.

[3] A. Apelblat, Volterra Functions, Nova Science Publishers, New York, 2008.

[4] A. ANSARI AND H. AsKARI, On fractional calculus of $\mathscr{A}_{2 n+1}(x)$ function, Applied Mathematics and Computation, 232 (2014), 487-497.

[5] A. ANSARI AND M. R. MASOMI, Some results involving integral transforms of Airy functions, Integral Transforms and Special Functions, 26 (7) (2015), 539-549.

[6] A. AnSARI The fractional airy transform, Hacettepe Journal of Mathematics and Statistics, 44 (4) (2015), 761-766.

[7] N. L. Balazs, H. C. Pauli And O. B. Dabbousi, Tables of Weyl fractional integrals for the Airy function, Mathematics of Computation, 33 (145) (1979), 353-358.

[8] A. BAUle AND R. FriedRICH, Joint probability distributions for a class of non-Markovian processes, Physical Review E., 71, 026101 (2005), 321-331.

[9] A. V. Chechkin, M. Hofmann AND I. M. Sokolov, Continuous-time random walk with correlated waiting times, Physical Review E., 80, 031112 (2009).

[10] D. G. Duffy, Transform Methods for Solving Partial Differential Equations, National Bureau of Standards, CRC Press, New York, 2004.

[11] K. Górska, A. Horzela, K. A. Penson and G. Dattoli, The higher-order heat-type equations via signed Lévy stable and generalized Airy functions, Journal of Physics A: Mathematical and Theoretical, 46, (2013), 16 pages.

[12] I. S. Gradshteyn And I. M. Ryzhik, Table of Integrals, Series, and Products, Elsevier Academic Press, Seventh Edition, New York, 2007.

[13] A. A. Kilbas, H. M. SRivastava And J. J. Trujillo, Theory and Applications of Fractional Differential Equations, Elsevier Amsterdam, 2006.

[14] J. Klafter, S. C. Lim And R. Metzler, Fractional Dynamics: Recent Advances, World Scientific, Singapore, 2012. 
[15] F. Mainardi, G. Pagnini and R. K. Saxena, Fox H-function in fractional diffusion, Messenger Math., 178, (1-2) (2005), 321-331.

[16] F. MAINARDI, Fractional Calculus and Waves in Linear Viscoelasticity, Imperial College Press., London, 2010.

[17] K. S. Miller And B. Ross, An Introduction to the Fractional Calculus and Fractional Differential Equations, Wiley, New York, NY, USA, 1993.

[18] L. Moslehi AND A. ANSARI, Some remarks on inverse Laplace transforms involving conjugate branch points with applications, Scientific Bulletin, Series A, Applied Mathematics and Physics, (2015), To appear.

[19] E. ORSINGHER AND M. D'Ovidio, Probabilistic representation of fundamental solutions to $\frac{\partial u}{\partial t}=$ $k_{m} \frac{\partial^{m} u}{\partial x^{m}}$, Electronic Communications in Probability, 17 (2012), 1-12.

[20] I. Podlubny, Fractional Differential Equations, Academic Press, San Diego, 1999.

[21] A. P. Prudnikov, Y. A. Brychkov And O. I. Marichev, Integrals and Series, Direct Laplace Transforms, Gordon and Breach, Vol 4, Amsterdam, 1992.

[22] W. H. REID, Integral representations for products of Airy functions, Zeitschrift fur angewandte Mathematik und Physik, 46, (1995), 159-170.

[23] W. H. REID, Integral representations for products of Airy functions Part 2: Cubic products, Zeitschrift fur angewandte Mathematik und Physik, 48, (1997), 646-655.

[24] W. H. REID, Integral representations for products of Airy functions, Part 3: Quartic products, Zeitschrift fur angewandte Mathematik und Physik, 48, (1997), 656-664.

[25] S. G. Samko, A. A. Kilbas And O. I. Marichev, Fractional Integrals and Derivatives: Theory and Applications, Gordon and Breach, Yverdon, Switzerland, 1993.

[26] T. Sandev, A. V. Chechinin, N. Korabel, H. Kantz, I. M. Sokolov and R. Metzler, Distributed-order diffusion equations and multifractality: models and solutions, Physical Review E., 92, 042117 (2015).

[27] T. SANDEV AND Z. Tomovs KI, Langevin equation for a free particle driven by power law type of noises, Physics Letters A., 378 (2014), 1-9.

[28] C. SCHUBERTA AND V. VARlamov, Integrals containing products of Airy functions and planar photon propagation in a magnetic field, Mathematical Methods in the Applied Sciences, 34, (2011), $1638-1648$.

[29] N. M. Temme and V. Varlamov, Asymptotic expansions for Riesz fractional derivatives of Airy functions and applications, Journal of Computational and Applied Mathematics, 232, (2009), 201215.

[30] O. Vallee And M. Soares, Airy Functions and Applications to Physics, Imperial College Press, London, 2004.

[31] V. VARLAMOV, Semi-integer derivatives of the Airy functions and related properties of the Kortewegde Vries-type equations, Zeitschrift fur angewandte Mathematik und Physik, 59, (2008), 381-399.

[32] V. VARLAmov, Fractional derivatives of products of Airy functions, Journal of Mathematical Analysis and Applications, 337, (2008), 667-685.

[33] V. VARLAMOV, Integrals involving products of Airy functions, their derivatives and Bessel functions, Journal of Mathematical Analysis and Applications, 370, (2010), 687-702.

[34] V. VARlamov, Differential and integral relations involving fractional derivatives of Airy functions and applications, Journal of Mathematical Analysis and Applications, 348, (2008), 101-115.

[35] V. Varlamov, Riesz fractional derivatives of the product of Airy transforms, Physica Scripta, T136 (2009) 014004 (5pp). 